\title{
The main problems of using biomass as a fuel
}

\author{
Dmitry Solovyev ${ }^{1,2}$, Liubov Shilova ${ }^{3, *}$, and Maksim Zheleznov ${ }^{3}$ \\ ${ }^{1}$ Shirshov Institute of Oceanology, Russian Academy of Sciences, Moscow, Russian Federation \\ ${ }^{2}$ Joint Institute for High Temperatures RAS (JIHT RAS), Moscow, Russian Federation \\ ${ }^{3}$ Moscow State University of Civil Engineering, Moscow, Russian Federation
}

\begin{abstract}
The article discusses the main problems of the using of biomass as a fuel, including the fuel use of biomass as an innovative way to generate clean energy. It is shown that according to the development of technology for the production of renewable energy sources, energy costs will decrease, and the operating time of the devices and, accordingly, their productivity will increase. Ultimately, this will allow to get a positive result, i.e. reduce harmful emissions from energy production. The methodology basis on the open statistics data and analysis of the energy balance of new energy production technologies are considered. The motivation for the using renewable energy sources in industrialized and developing countries is investigated. A review of new technologies for the using biomass as a fuel is made, which allows for efficient processing of biomass, including gasification, co-production of heat and electricity, fuel use of combustible gases generated at landfills, and production of fuel for transport in the form of methanol and biodiesel.
\end{abstract}

\section{Introduction}

Priorities in the use of various types of fuel and energy resources are changing quite quickly. At the beginning of the nineteenth century, wood was the main type of fuel; at the end of the century, coal was the first consumption. At that time, the share of oil and natural gas in the total balance did not exceed a few per cent. By 1975, the share of coal was less than $30 \%$, about the same was accounted for by natural gas, while oil consumption became decisive and exceeded $40 \%$. Since the mid-1970s, there has been a relative decline in oil consumption, and the share of natural gas in the total balance of used fuel and energy resources has been increasing.

The sequence of priority use of various types of fossil fuels corresponds to their location in the row of reducing the harmful impact on the environment. Natural gas is the cleanest fuel; environmental pollution from the use of petroleum products is less than from coal combustion.

The technology of using fossil fuels in its development goes through several stages. Initially, the fuel is used only in pure form. In the future, technologies for its processing appear, which make it possible to organize efficient combustion of fuels in power plants and at the same time obtain products necessary for industrial processes.

\footnotetext{
* Corresponding author: ShilovaLA@ mgsu.ru
} 
In the 21 st century, oil, gas and products of their processing will play a decisive role in the world fuel and energy balance. This fact is confirmed by a large number of publications [1-11]. The fact that the main reserves of oil and gas are concentrated in a limited number of regions, mainly in the Middle East and Russia will have a significant impact on the world economic system now and in the long term. The "geography" of the distribution of fuel and energy resources, as is known, in many cases is a factor determining the geopolitical interests of developed industrial countries. Hence the somewhat different attitude of Russia, as a country with abundance endowed with natural resources and being their exporter, to Western concepts of the dominant trends in the structure of interstate relations. When making forecasts for future energy development, the fact that in the modern world one-third of the world's population living in underdeveloped countries accounts for only $10 \%$ of the world's energy production is taken into account. The growth of prosperity in developed countries, integration into the world economic system of China, India and other countries will lead to a significant increase in energy consumption. Despite the implementation of an active policy to save fuel and energy resources, according to most forecasts, energy needs by 2030 will increase by more than half, while $60 \%$ of the expected increase will be provided by oil and gas production. The fastest growth will be the production of electricity, which, according to existing estimates, will double by 2050 [12].

The Kyoto Protocol dictates certain restrictions on the use of fossil fuels, primarily coal. It is believed that the share of coal in the production of energy resources will be approximately $40 \%$ for the period up to 2025 and its amount used in the energy sector will not increase in the future. Even though there are significant reserves of coal in the world, the main problem associated with the expansion of its use in the fuel and energy complex is the harmful impact on the environment of the products of its combustion [13].

\section{Methodology}

\subsection{The methodology of analysis of the fuel and energy balance of new energy production technologies}

There are two main reasons for involving new energy production technologies in the fuel and energy balance. The first reason is to ensure the energy security of countries that do not have their own fossil fuel reserves. The second is the urgent need to solve environmental problems arising from the energy use of fossil fuels. Among the "environmental" problems, the disruption of the natural balance of carbon is, apparently, the main reason for which the development of new methods of obtaining energy is becoming increasingly important. In this regard, considerable attention is paid to the development and practical use of renewable energy sources, which, in the first approximation, make it possible to obtain energy by environmentally friendly methods. In fact, in the production of wind turbines, solar panels, hydroelectric power plants, etc. the costs of organic fuels are necessary, which is accompanied by the corresponding emissions of harmful substances into the atmosphere 1[4]. A positive integral effect in reducing harmful emissions into the atmosphere can be achieved provided that the costs of fossil fuels for materials and manufacturing of equipment for obtaining "renewable" energy, as well as the costs of their disposal after the end of their service life, will be less than the energy produced by these devices for operating time. Obviously, with the development of technology for the production of renewable energy sources, energy costs will decrease, and the operating time of the devices and, accordingly, their productivity will increase. Ultimately, this will allow you to get a positive result, i.e. reduce harmful emissions from energy production. In 2020, energy from renewable sources 
in Europe for the first time produced more energy from renewable sources than from traditional sources [15].

Fuel use of biomass is the most profitable method for producing environmentally friendly energy [16]. This is due to several objective reasons. Plant waste, such as wood waste, is on average $50 \%$ carbon. This carbon in the process of decay is the main source of carbon dioxide emissions into the atmosphere. The idea of fuel use of plant waste is quite simple. The release of carbon dioxide during the decay of plant waste, including wood waste, is the same as when they are burned in power generating units. Thus, the fuel use of carbon-containing waste of plant (natural) origin does not disturb the natural balance of carbon. The use of plant waste in the form of fuel or raw materials for industrial technologies will reduce the carbon consumption of fossil fuels, thereby reducing the emission of carbon dioxide which is the end product of the conversion of carbon from natural fuels in energy and technological processes.

Progress is always unprofitable. This eschatological idea is reflected in the apocalyptic expectations adopted in Christianity, Islam and Judaism. In this case, the development of the fuel and energy complex is always accompanied by a negative impact on the natural balance. The question of how humanity can solve this problem, prevent global changes in the natural balance, and ultimately preserve the necessary conditions for life on the planet remains open. Of course, the use of renewable energy sources known to us at present will not be able to bring a significant effect. This question is more philosophical and theological, but not technical. A new character of thinking must be formed in humanity to solve this global problem. We can only hope that this thinking will be acquired under the influence of pressing circumstances, and on this basis, technical solutions will be developed to get out of the impending crisis.

The environmental load, primarily the natural carbon balance, changes not only under the influence of the fuel and energy complex. As a result of the increase in the productivity of crops (for eighty years, the yield of cereals increased from 13-16 to 60-80 centners/hectare), the "load" on arable land associated with the processing of agricultural waste has significantly increased. The same can be said for animal waste. If earlier, with a yield of 20-25 centners/hectare, livestock waste could be used to fertilize arable land on which livestock feed was grown, but with modern technologies, the same amount of feed is grown on an area three times smaller. Now the received amount of manure is excessive for a given area, and it becomes necessary to utilize it not in the form of fertilizers, but by some other method. The growth of the world's population leads to a decrease in the area of forests, which are the main sink of carbon dioxide formed as a result of processing (decay) of plant waste. Finally, the use of biomass for fuel, meaning traditional methods, is a familiar and available source of energy resources. Biomass and waste are found almost everywhere, and their use is an affordable and common method of obtaining energy resources. In the general case, from garbage and waste of various origins, including agricultural production, which still needs to be removed and disposed of, you can get a useful product in the form of energy resources. And it is quite natural that this opportunity is the most attractive for practical implementation.

\subsection{The analysis of statistics of RES and bioenergy use in industrialized and developing countries}

The motivation for using renewable energy resources (RES) in industrial and developing countries is different. The former has a developed infrastructure for the use of organic fuels, but most of them are imported, as a rule (from the point of view of Western analysts), from countries with unstable political systems. For these countries, the use of renewable energy sources is a step towards ensuring energy security. A significant incentive in the development of renewable energy sources is the need to reduce the environmental load from the fuel and 
energy complex and, finally, constantly growing prices for fossil fuels. For underdeveloped and developing countries, the motivation is somewhat different. The use of renewable energy resources is the simplest and cheapest method to meet the urgent needs of the population in energy resources.

Global primary energy consumption in 2019 was 158,839 TWh. Approximately 7\% of this amount was biomass used in a traditional way or after processing based on modern technologies. In fig. 1 shows a diagram of the use of various types of primary energy consumption in the world from 1970 to 2019 [13].

Peat is also a renewable energy resource. It would be more correct to classify peat as a "partially renewable" energy resource, since according to various data, during the extraction of peat, from 8 to $15 \%$ of reserves are restored annually. For the energy sector of our country, peat can be of great importance. For these reasons, a separate chapter in this report will be devoted to the problem of the possible development of "peat energy".

More than $90 \%$ of biomass is used unprocessed: firewood, plant and household waste, mainly in developing and underdeveloped countries, which account for about a third of the world's population.

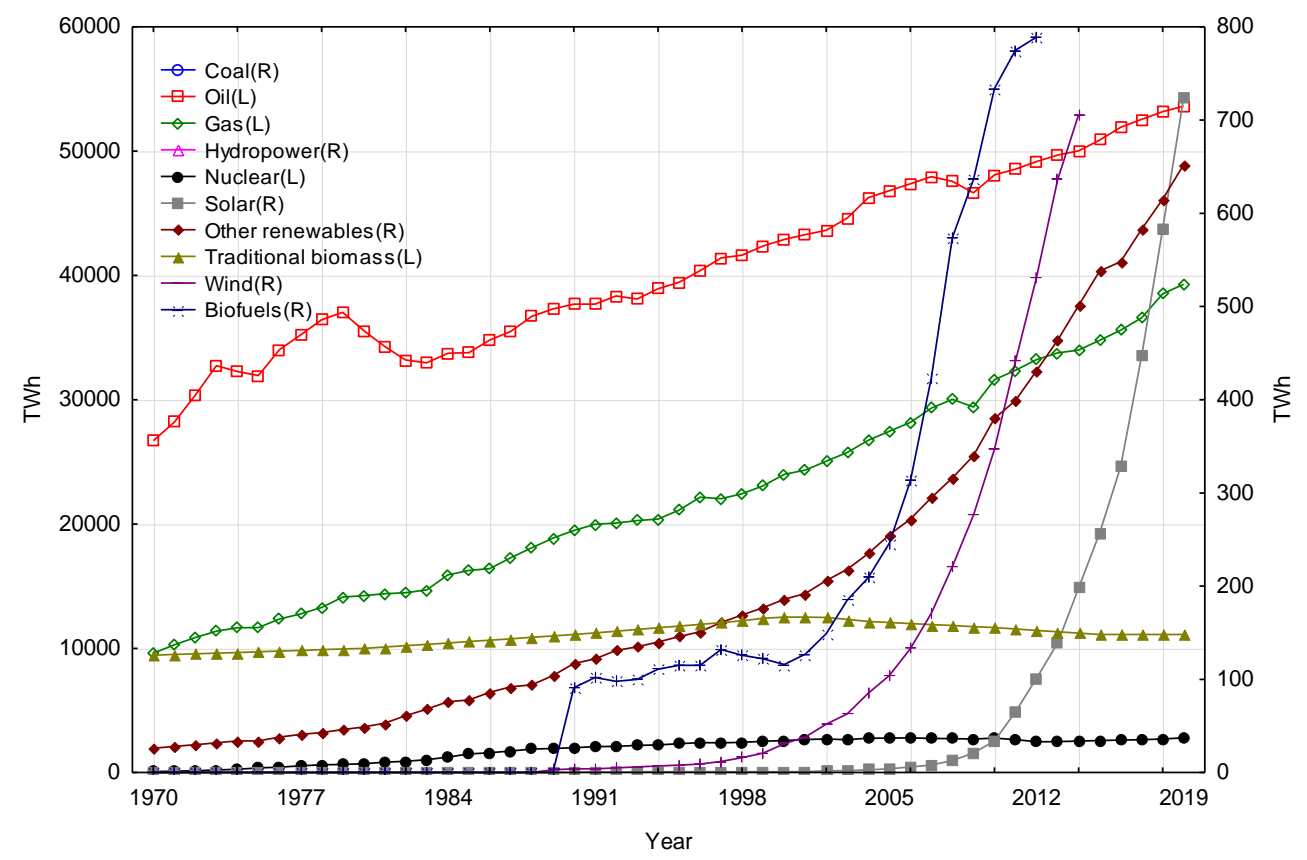

Fig. 1. Use of various fuels in world energy consumption from 1970 to 2019. Source: Compiled by the authors using data from [17]

About $10 \%$ of the total energy consumption of biomass falls on processed types of biofuels used to generate electricity and heat.

Modern technologies for the fuel use of biomass make it possible to process it, including gasification, a joint production of heat and electricity, fuel use of combustible gases generated at landfills, to obtain fuel for transport in the form of methanol and biodiesel. 


\section{Results and discussion}

\subsection{The innovative technologies of biomass fuel use}

Depending on the properties of "organic raw materials", various technologies of its energy use are possible. For the use of dry biomass, thermochemical technologies are most effective (direct combustion, gasification, pyrolysis, etc.). Biochemical processing technologies to produce biogas (anaerobic decomposition of organic raw materials) or liquid biofuels (fermentation processes) are most effective for wet biomass.

Gasification of wood waste provides for the production of fuel gas, the basis of which is $\mathrm{CO}, \mathrm{H}_{2}$ and $\mathrm{N}_{2}$ and which can be used as a gaseous fuel in boiler houses, gas turbines and internal combustion engines.

Direct combustion of wood is well known at the household level. The technology of energy use of wood waste is constantly being improved. Relatively recent technology for producing pellets from wood waste has become widespread in many industrialized countries. Pellets are used in standard power units operating on liquid, gaseous and solid fossil fuels with the appropriate reconstruction of furnaces and the creation of the necessary infrastructure for storage and preparation of fuel.

Among biochemical technologies for processing liquid organic waste, the most widely used technology in many countries of the world is the technology of anaerobic (in the absence of atmospheric oxygen) decomposition of organic raw materials to obtain biogas, consisting of $55-60 \%$ of methane.

The produced biogas is taken out of the digester and sent to a gas holder - an accumulator, from where gas is taken as needed, mainly for heating nearby objects. Biogas can also be used as a fuel in internal combustion engines for the production of mechanical and/or electrical energy.

In many countries, comprehensive research is being carried out to develop technologies for producing motor fuel from biomass. The most significant results in this direction were obtained in Brazil in the production of ethanol, which successfully competes with gasoline.

In European countries, the use of biomass for fuel has been steadily increasing over the past several years [18]. Thus, according to the data of [18], in the European electric power industry biomass is mainly used for the production of electricity at thermal power plants. At the same time, the share of biofuels in a generation is relatively small - only $6 \%$, while the total share of renewable energy sources in the electricity of the EU is about $30 \%$. Among all types of renewable energy, biofuels are the third most important source of energy (17\%) after hydropower and wind. Bioenergy accounts for the largest share in electricity production in Finland (18\%) and Denmark (19\%), as well as in the Baltic countries, which are welldeveloped in the UK, Germany, Hungary and Belgium, and in several countries (Greece, Cyprus, Malta, Romania, France), its share in production does not exceed 1\%, which is associated with both climatic characteristics and the availability of appropriate resources. Bioenergy is most in-demand in northern and northeastern Europe, where resources are abundant and the relatively cold climate requires high demand for district heating.

In many developed countries, public policy is aimed at the development and support of renewable energy sources. There are many forms of such support: tax policy, government subsidies for the production of renewable energy sources, low-interest rates on loans, etc. In the European Union, a directive has been adopted that obliges all countries of the community to bring the by 2030 share of renewable energy sources to $32 \%$ of total energy consumption. Some states in the United States have similar regulations.

The existing data on the available energy potential of plant waste in Russia are rather contradictory. According to experts, for energy purposes in our country, it is technically possible to annually use up to 800 million tons of woody biomass, up to 400 million tons (dry 
matter) of organic waste (from agricultural production - 250 million tons, from the forest and woodworking industry - 70 million tons), up to 60 million tons of municipal solid waste and up to 10 million tons of municipal sewage sludge [19]. In the literature, there are also other estimates of the available energy potential of Russian production wastes. All of them give deliberately large values about the assessment of the available biofuel potential in Western Europe, carried out by Western colleagues. So, based on a fairly detailed consideration, the total potential of wood waste in Western Europe is estimated at 245 million cubic metres. This content includes waste from felling trees (branches, small size, stumps, etc.) in the amount of 173 million cubic metres annually, 63 million cubic metres annually harvestable felling resides, about 9 million cubic metre remains in the form of stumps [20].

Bioenergy development projects in the countries of the European Community also take into account the fact that in the countries of "old Europe", the amount of biomass, including wood and wood waste suitable for energy use, is very limited, and there are practically no reserves of arable land. In this regard, plans for the development of industrial biomass production in countries that have recently joined the European Community: Estonia, Latvia, Lithuania, Poland, Romania, Bulgaria, Hungary, the Czech Republic and Slovakia are actively being drawn up [21]. Thus, the "young European countries" are assigned a purely "raw material" role in restructuring the energy supply of the countries of "old" Europe.

\subsection{Russian technologies for the use of biomass energy}

In this regard, the possible role of Russia as a world energy power is interesting. Russia occupies one of the leading places in the production of organic fuels. Along with the reserves of fossil fuels, Russia with the development of technologies for the energy use of biomass in terms of its resource potential in the future may take a leading place in the production of environmentally friendly fuels from biomass, including wood and wood waste. Up to $23 \%$ of the world's timber reserves are concentrated on the territory of our country. A prerequisite for the transformation of Russia into a leader in the production of environmentally friendly fuels from biomass, in particular from wood waste and wood processing waste, is the development of new modern technologies for converting wood into fuel, as well as into raw materials for industrial technologies.

Due to its relatively low calorific value and low density, wood and wood waste are inconvenient to transport. The most promising is wood processing for further use at the production site. We will call this stage, by analogy with the terminology used in the commodity sector, enrichment. "Carrying", especially in the conditions of our country, is not wood, but the products of its processing, i.e. "Enriched" wood. Considering that wood, on average, consists of $50 \%$ of carbon, from our point of view, the technology of obtaining pure carbon materials from wood waste, developed by the authors of this report, has significant prospects. These materials can be used as an environmentally friendly high-calorific fuel and as a raw material for many industrial technologies that use pure carbon materials in their production.

Replacing traditional hydrocarbon fuels with wood products and wood waste is covered by the Kyoto Protocol and will provide additional funds by trading on the $\mathrm{CO}_{2}$. Obviously, when organizing the industrial production of high-calorie environmentally friendly fuel from wood waste, this product will be in demand on the international market and will be another export type of fuel and energy resources produced in Russia.

The introduction of technologies for obtaining fuels from the huge reserves of wood available in the country will allow solving the problem of creating "distributed energy", i.e. local production of electricity and heat, which is necessary for the reliable provision of energy supply "locally", which is an integral part of the country's energy security strategy. 


\section{Disscussion and conclusion}

Projected growth in global energy consumption for the period up to 2025 will average $2 \%$ per year. The development of renewable energy sources will be active. It is assumed that the use of biomass energy will increase by $6 \%$ per year, and the use of solar and wind energy converters by $30 \%$. However, an increase in the contribution of renewable sources to the overall fuel and energy balance, as mentioned above, will not fully solve the problems associated with energy security and environmental problems caused by dependence on fossil fuels. This primarily applies to countries that do not have their fossil fuel resources. The solution to this problem requires the development of non-traditional methods of energy production in the current practice.

The work was carried out within the framework of state assignment No. 0149-2019-0002; AAAAA19-119020690085-9

\section{References}

1. P. Ning, G. Yang, L. Hu, Z. Wang, J. Yang, ect., Bio. For Bio. 14(1), 102 (2021)

2. N. Gabbanelli, E. Erbetta, M.E. Sanz Smachetti, ect., A.C. Pontaroli, M.M Echarte, Bio. For Bio. 14(1), 85 (2021)

3. H. Zhao, D. Lu, J. Wang, B. You, H. Li, ect., Nat. Com. 12(1), 78 (2021).

4. Q.Yang, H. Zhou, P. Bartocci, C.P. Nielsen, M.B. McElroy, ect., Nat.Com. 12(1), 1698 (2021)

5. J.M. Moradian, Z. Fang, Y.-C.Yong, Bio. and Bio. 8(1), 14 (2021)

6. T.T. Cuong, H.A. Le, N.M. Khai, N.D. Tri, N.X. Huan, ect., Sci.Rep. 11(1), 792 (2021)

7. A. Colantoni, M. Villarini, D. Monarca, E. Bocci, S. Rajabi Hamedani, ect., Ene.Rep. 7, $1954(2021)$

8. Y.Wang, Q. Van Le, H. Yang, ect., Che. 281, 130835 (2021)

9. K. Rabea, A.I. Bakry, A. Khalil, M.K. El-Fakharany, M. Kadous, Fuel 300, 120976 (2021)

10. H. Perazzini, M.T.B. Perazzini, F.B. Freire, J.T. Freire, Ren.Ene. 175, 167 (2021)

11. M. Y. Berezkin, V. A. Butuzov, V. V Bushuev, K. S. Degtyarev, V. M. Zaichenko, A. M. Zalikhanov, O. Y. Kalinina, A. M. Karpachevskiy, L. V Nefedova, A. M. Nechayev, R. I. Nigmatulin, E. N. Popova, F. V Sapozhnikov, O. A. Sinyugin, A. A. Solovyev, D. A. Solovyev, and M. N. Shilyakina, Energy Study, Geography and Environmental Earth (Energia, Russia, 2020)

12. V. M. Batenin, V. V. Bushuev, N.I. Voropay, Innovative Power Industry - 21 (Energia, Russia, 2017)

13. L. S. Plakitkina, Analysis and Prospects for the Development of the Coal Industry of the Main Countries of the World, the CIS and Russia in the Period Until 2030 (Mining industry, Russia, 2013)

14. A. A. Solovyev, D. A. Solovyev, L. A. Shilova, IOP Conf. Ser. Mater. Sci. Eng. 012162 (2021)

15. Energiewende A. et al. The European Power Sector in 2019: Up-to-Date Analysis on the Electricity Transition (Berlin, 2020)

16. V. M. Zaychenko, Reg. Ene. and Ene. 1, 88 (2019)

17. Global direct primary energy consumption (2021) (URL: https://ourworldindata.org/grapher/global-primary-energy?country)

18. A. V. Zimakov, Wor.Ec. and Int. Rel. 64, 81 (2020)

19. V. M. Zaychenko,U. V. Faleeva, Ecol. Ind. and Ene. Saf. 1, 417 (2018)

20. V. Batenin, V. Zaychenko, V.F. Kosov, V.A. Sinelchekov, Rep. of the Aca. of Sci., 
446(2), 179 (2012)

21. V. M. Zaychenko, A. A. Chernyavskiy, V. V. Kuvshinov, E.G. Kakushina and C. A. Abeydulin, Ene. Pla. and Tech. 5, 53 (2019) 